\title{
MATERIAL DIDÁTICO E PRÁTICA DOCENTE
}

Rosilene Batista de Oliveira Fiscarelli ${ }^{1}$

\section{Resumo}

O presente trabalho objetiva discutir o discurso docente acerca dos materiais didáticos, a partir da análise das práticas discursivas construídas pelos professores em torno desses objetos no ensino, apoiando-se nos estudos foucaultianos sobre discurso e construção de conhecimento. Os dados analisados durante a pesquisa foram coletados a partir de entrevistas com professores da rede pública de ensino paulista. Os resultados das análises realizadas conduzem-nos a pensar um pouco mais sobre esses materiais no cotidiano escolar; na maneira como os professores concebem esses materiais e apropriam-se deles em sua prática docente; nas implicações que surgem ao introduzir-se materiais no ensino e nas maneiras e possibilidades de preparar os professores para essas implicações. Ao compreendermos os materiais didáticos no processo de desenvolvimento profissional do professor, abrimos possibilidades de superação de obstáculos que venham inibir o espaço de experimentação e o crescimento profissional a partir da utilização desses materiais em sala de aula.

\section{Introdução}

O presente trabalho tem como objetivo discutir os saberes dos professores sobre a utilização de materiais no ensino, a partir da análise discursiva desses enunciadores. Considerando que esses saberes originam-se não somente de saberes instituídos (CARBONNEAU, M; HÉTU, J.,2001), mas principalmente daqueles provenientes da experiência cotidiana em sala de aula, acreditamos que a análise desses discursos possa contribuir para compreendermos as relações estabelecidas entre prática docente e material didático, auxiliando-nos no direcionamento e formulação de propostas de formação docente que venham de encontro ao desenvolvimento da profissionalização quanto a utilização de materiais didáticos.

Optamos por utilizar durante a pesquisa o termo material didático, por este parecer ser o mais usado no dia-a-dia da escola, sugerindo também uma abordagem ampla de utilização de vários tipos de objetos. Entende-se aqui por material didático todo ou qualquer material que o professor possa utilizar em sala de aula; desde os mais simples como o giz, a lousa, o livro didático, os textos impressos, até os materiais mais sofisticados e modernos.

Fazer uso de um material em sala de aula, de forma a tornar o processo de ensino aprendizagem mais concreto, menos verbalístico, mais eficaz e eficiente, é uma preocupação que tem acompanhado a educação brasileira ao longo de sua história. Historicamente, o uso de materiais diversificados nas salas de aula, alicerçado por um discurso de reforma educacional, passou a ser sinônimo de renovação pedagógica, progresso e mudança, criando uma expectativa quanto à prática docente, já que os professores ganharam o papel de efetivadores da utilização desses materiais, de maneira a conseguir bons resultados na aprendizagem de seus alunos.

Ao considerarmos importante os saberes dos professores sobre os materiais didáticos, abrimos mais um espaço para vermos estes profissionais como sujeitos de sua prática, e portanto capazes de refletir e colaborar com a construção dos saberes que rodeiam a utilização dos materiais didáticos na sala de aula. Desta forma, é importante repensarmos que tanto a formação inicial dos professores quanto as atividades de formação continuada, devem considerar não somente o ideário pedagógico existentes sobre esta utilização dos materiais didáticos como também os saberes e experiências vividos por esses profissionais, na escola .

\footnotetext{
${ }^{1}$ UNESP - Faculdade de Ciências e Letras de Araraquara- Programa de Pós-Graduação em Educação Escolar. fiscare@yahoo.com.br
} 


\section{Um discurso construído}

O termo discurso, aqui utilizado, parte de uma conceituação apoiada nas idéias de Michel Foucault sobre análise discursiva. $\mathrm{O}$ discurso, a partir deste referencial teórico, ultrapassa a mera utilização de letras, palavras e frases que expressam "algo" na linguagem humana. Não ignorando, no entanto, que os discursos são feitos de signos, mas olhando-os como construções históricas (FOUCAULT, 2000).

Consideramos que o conjunto de saberes, valores e significados construídos em torno de um objeto é que o faz tornar-se útil ao processo de ensino-aprendizagem, transformando-o em um material didático, e que esses saberes criam "regimes de verdade" dominantes, capazes de orientar nossa visão e pensamento sobre "como" ensinar. Assim, em torno dos materiais didáticos tem se construído, ao longo da história da educação brasileira, um discurso que legitima sua utilização em sala de aula, salientando as suas potencialidades rumo a um ensino moderno, renovador, eficiente e eficaz.

O termo "regimes de verdade" é utilizado por Foucault para conceituar as normas, regras, padrões que interferem e formam as práticas sociais. Para Foucault (2001), cada sociedade, em uma determinada época, cria seus regimes de verdade; isto é, os tipos de discursos que são tomados como verdadeiros e que são valorizados por esta sociedade. Desta forma, as práticas escolares atuais, relacionadas à utilização dos materiais didáticos, estão imersas nas "verdades" que foram construídas e que estruturaram e ainda estruturam os saberes sobre esses materiais, e nos significados que os mesmos adquiriram ao longo da história da educação. Os materiais didáticos, antes simples objetos, passam a adquirir significados importantes na concretização e efetivação de novas propostas educacionais, direcionando e definindo nossas visões sobre o que é ser um "bom professor", o que "é dar uma boa aula", o que é ser uma "boa escola" e o que é melhor ser utilizado em sala de aula.

São vários os enunciadores do discurso sobre o material didático. Entre eles, podemos citar, o discurso da política educacional, o discurso pedagógico e o discurso dos professores. Cada um desses enunciadores participa e contribui para a construção de um saber sobre os materiais no ensino, para a construção de um discurso que rodeia esses objetos. Porém, é importante considerarmos que há especificidades nas práticas discursivas desses enunciadores, relacionadas ao lugar que ocupam no campo educacional e ao contexto nos quais estão inseridos.

Assim, neste trabalho discutiremos os resultados obtidos a partir da análise das práticas discursivas dos professores, considerando que o saber que o professor traz, em si mesmo é formado por outros saberes, mas também são as marcas de seu trabalho e das condições, situações e recursos ligados a este trabalho (TARDIF, 2002).

\section{Os professores}

No intuito de conhecermos os significados e valores que os professores constroem em torno dos materiais didáticos, bem como encontrarmos possibilidades de respostas para nossas questões iniciais, realizamos entrevistas semi-estruturadas com 9 professores que lecionam numa mesma escola pública de ensino fundamental - ciclo II, em Araraquara- SP, as disciplinas de português, matemática, geografia, história, ciências, artes e inglês.

A entrevista foi escolhida como instrumento de coleta de dados por possibilitar o conhecimento das práticas discursivas de seus participantes formadas por "sistemas de valores, de condições, normas e símbolos e ao mesmo tempo ter a magia de transmitir as representações de grupos determinados em condições históricas, sócio-econômicas e culturais específicas" (MINAYO, 2000, p.110). Para a realização das entrevistas foi elaborado um roteiro que pudesse levar os professores a dizerem o que sabem e o que pensam sobre os materiais didáticos. Este 
roteiro foi testado, analisado e posteriormente demos continuidade às entrevistas. Nossa preocupação, no momento de elaboração do roteiro, consistia em não estabelecer e nem trazer significados cristalizados sobre os materiais didáticos aos professores, mas sim levá-los a falarem e mostrarem quais os saberes e significados que constroem em torno desses materiais, a partir de perguntas relacionadas às situações e relações que os mesmos estabelecem no interior e exterior do ambiente escolar. Portanto, trabalhamos os temas de forma mais ampla e genérica, no intuito de identificar nas "entrelinhas" do discurso docente os significados estabelecidos aos materiais didáticos, evitando ao máximo a indução de concepções.

Apresentamos, neste momento, a análise dos dados coletados a partir das entrevistas realizadas com os 9 professores participantes. Com o objetivo de orientar nosso "olhar" para as respostas dadas pelos professores, buscamos encontrar nelas significados que foram recorrentes no discurso pedagógico, também analisado no decorrer da pesquisa a partir dos dados coletados em manuais de Didática, e no discurso da política educacional paulista. ${ }^{i}$ Desta forma, primeiramente procuramos definir a conceituação que os professores dão aos materiais didáticos, bem como identificar o que reconhecem como material didático e as vantagens que vêem na sua utilização em sala de aula. Posteriormente, buscamos verificar se no discurso dos professores reapareciam significados cristalizados sobre os materiais didáticos, tais como: concretizadores do conhecimento, motivadores, facilitadores da aprendizagem, eficientes e eficazes, organizadores e estruturadores do conteúdo a ser ensinado.

Ampliando a análise para a questão da prática docente, destacamos a importância que os materiais didáticos assumem nesta prática e o papel que desempenham na conquista da autonomia docente. Ainda referindo-nos a prática docente, procuramos nas práticas discursivas docentes as dificuldades apresentadas na utilização de um material, no que diz respeito ao processo de apropriação dos mesmos pelos professores e pelos alunos.

A existência de uma relação entre material didático e conteúdo a ser ensinado também foi analisada no discurso dos professores entrevistados, de maneira que conhecêssemos como esta relação é estabelecida na prática docente (GIMENO,2000). Desta forma, não nos prendemos a categorias pré-estabelecidas, mas fomos construindo nossos focos de análise no decorrer do desenvolvimento da mesma, seguindo as pistas que os professores iam deixando em suas práticas discursivas e relacionando-as com a forma como os manuais de Didática e a publicação "A escola de cara nova:sala-ambiente" concebiam os materiais didáticos em seus discursos. Na busca de novas "verdades" sobre o material didático, relacionamos o discurso já legitimado sobre ele e o discurso construído pelos professores, num contexto voltado ao cotidiano das salas de aulas.

\section{O que dizem os professores}

Os materiais didáticos são considerados pelos professores como instrumentos importantes à prática docente, vendo-o como material auxiliar desta prática. Em vários trechos das entrevistas verificamos isto, principalmente quando os professores conceituam o material didático.

É o material que vai me ajudar na sala de aula, auxiliar na tarefa de transmitir para o aluno o que eu quero (PROFESSOR A).

Os professores entrevistados reconhecem como materiais didáticos vários objetos, desde os mais tradicionais como o giz, a lousa e o livro didático, até os mais modernos como os computadores. O retroprojetor, o episcópio, o microscópio, a televisão, o vídeo, o jornal, as revistas, os livros paradidáticos, os dicionários, os mapas, os atlas, os textos xerocados, a música, os jogos, a

\footnotetext{
${ }^{2}$ Além do discurso docente, também analisamos o discurso pedagógico presente em 3 manuais de Didática: Introdução a Didática Geral de Imídeo Giuseppe Nérici, Sumário de Didática Geral de Luiz Alves de Mattos e Planejamento de Ensino e Avaliação de Clódia Maria Godoy Turra e autoras. Analisamos o discurso da política educacional paulista, presente na publicação A Escola de Cara Nova: sala ambiente, da SEE- SP, 1997.
} 
sucata, os papéis coloridos, a cola, a tesoura, os lápis e canetas, o caderno, as folhas de papel, os slides, as lâminas, os aparelhos multimídias, todos esses objetos têm suas potencialidades reconhecidas pelos professores para o uso em sala de aula, independente de serem disponibilizados na escola em que lecionam. A música, os exercícios escritos também foram reconhecidos pelos professores como materiais didáticos, mostrando que os mesmos possuem uma concepção ampliada sobre o que podemos chamar de material didático. Os materiais didáticos dinamizam a aula, facilitam a aprendizagem, atraem a atenção, mantêm os alunos ocupados, motiva-os, despertando o interesse pela aula, conforme as seguintes palavras de alguns professores, essas são algumas das vantagens que uso do material didático oferece.

Os professores vêem no uso do material didático oportunidades de proporcionar uma participação mais ativa dos alunos durante as aulas. Somente a fala dos professores, muitas vezes, não desperta a atenção do aluno, cansando tanto aluno quanto professor. Os materiais didáticos quebram o excesso de verbalismo e concretizam o assunto abordado pelo professor, facilitando a aprendizagem do aluno, diminuindo os esforços do professor. Enfim, tornam a aula mais interessante e prazerosa para ambos.

[...] porque, prá começar, só a nossa figura humana, quanto educador, não atrai. O material didático ele enriquece e o aluno gosta de manusear, de ver. Então a visão das coisas, o manuseio enriquece a aprendizagem" (PROFESSOR D).

Porém, apesar de todas as vantagens e a importância que os professores destacam na utilização dos materiais didáticos, eles não ocupam um lugar central no bom desempenho da prática docente, segundo as falas da maioria dos professores entrevistados. Frente a um professor competente, o material didático é irrelevante, quase supérfluo, pois nada substitui a presença do professor. O bom professor pode motivar e incentivar seus alunos, despertando-os para o conhecimento e obtendo resultados positivos de aprendizagem somente com a sua vontade e competência profissional, além de seu carisma e a maneira como interage com seus alunos.

Mas ainda o melhor material didático é o professor conversar com o aluno sobre o conteúdo. O professor ainda tem um papel importantíssimo. Não existe assim nada que substitui o professor, nada. Eu não vejo o material melhor do que o professor (PROFESSOR E).

O caráter de objetividade e materialidade dos materiais didáticos não é dispersado nas práticas discursivas docentes, pois os professores reconhecem esses materiais como simples objetos, incapazes de por si só mudarem as práticas, inovando-as dentro da sala de aula. Somente a presença dos materiais didáticos na sala de aula não é capaz de transformar positivamente o processo de ensino-aprendizagem. Para os professores, o professor deve saber utilizá-lo, saber incorporá-lo em sua prática cotidiana, de acordo com as condições estruturais de sua escola e as necessidades de seus alunos.

Conforme esses trechos, para os professores, a prática docente é auxiliada pelos materiais didáticos, mas não depende estritamente deles para realizar-se de maneira satisfatória. Há uma essência que a estrutura, norteando todas as ações docentes na sala de aula em relação ao uso de materiais didáticos: a experiência. É a partir da experimentação, do acerto e erro que os professores utilizam-se de um material didático em sala de aula, concebendo esta experimentação como uma oportunidade de crescimento, amadurecimento profissional e conquista de sua autonomia. A seleção e elaboração do próprio material didático a ser usado em aula é um momento importante para o exercício desta autonomia. Os materiais didáticos selecionados e escolhidos pelos professores são aqueles que, primeiramente, dão segurança a eles quanto à maneira de usá-los e à receptibilidade dos alunos.

Os professores "confiam" nos materiais que acostumaram a utilizar durante sua experiência profissional. No entanto, também estão sempre atentos à adequação deste material ao grau de maturidade de seus alunos, ao grau de interesse e atenção que podem despertar neles e às 
possibilidades de relações que podem estabelecer entre o assunto da aula e o material didático utilizado.

Nas práticas discursivas dos professores, percebemos que o domínio da atenção dos alunos, a aquisição de práticas de leitura e escrita e a fixação da matéria são aspectos positivos que o uso do giz e da lousa podem trazer ao ensino.

Principalmente na minha área, de matemática, eu tenho que estar indo para a lousa. Tenho que estar fazendo exercício, mas tem a sala de informática. Mas eu não estou apta para estar indo lá, elaborando exercícios com os alunos. Eu tenho um pouco de dificuldade com esta nova tecnologia. Eu uso muito a lousa (PROFESSOR C).

Em relação ao uso do livro didático, os professores têm opiniões diferenciadas. Alguns consideram importante o uso deste material e queixam-se de não o terem disponível para o ensino da sua disciplina, como inglês e artes. Outros professores acreditam que o uso do livro didático torna a aula cansativa, monótona. É preciso inovar com materiais diferentes, que estimulem o aluno e também o professor, pois alguns professores sentem-se presos quando usam o livro didático, preferindo utilizarem textos pré-selecionados e organizados por eles mesmos. Sentem-se mais seguros, mais satisfeitos com o seu trabalho em sala de aula.

Para outros professores, o livro didático é essencial para a organização do conteúdo, direcionando o aluno para o estudo de determinada disciplina. Também o seu uso diminui a utilização da lousa, poupando o aluno da cópia do assunto colocado nela. Neste sentido, o livro didático é concebido como um material básico, necessário para nortear o professor e o aluno.

Em relação à disponibilidade de materiais didáticos na escola, a sala-ambiente é vista pelos professores como um lugar eficiente, dinamizador de sua prática e principalmente motivador da aprendizagem do aluno. A eficiência da sala-ambiente, para os professores, consiste na disponibilização de todos os materiais didáticos necessários ao ensino de uma determinada disciplina, estando sempre a mão, fazendo com que o professor gaste menos tempo para procurá-los pelas dependências da escola e organizá-los para o ensino em sala de aula.

Na sala-ambiente, a exposição dos trabalhos realizados pelos próprios alunos, em casa ou no momento da aula, é considerada pelos professores um fator importante para a aprendizagem, já que os alunos sentem-se estimulados ao ver seus trabalhos expostos nas paredes da sala de aula. No entanto, ambientalizar não é somente expor objetos e trabalhos dos alunos, mas sim transformar a sala de aula num espaço propício para o ensino, num cenário onde a aula irá acontecer de maneira mais fácil e prazerosa. Os objetos, transformados em materiais didáticos, é que comporão este cenário.

Observamos que a não utilização de determinados materiais didáticos na sala de aula não está ligada aos significados que os mesmos adquirem na prática docente, pois esses são positivos e reiteram a importância desses objetos para o ensino. Além do sentimento de despreparo, os professores apontam outros aspectos dificultadores desta utilização, relacionados a fatores internos e externos ao ambiente escolar, os quais influenciam no efetivo uso de alguns materiais didáticos. Dentre estes aspectos, os mais relevantes são: a quantidade insuficiente de materiais didáticos ao grande número de alunos por turma; a falta de pré-requisitos dos alunos, o pouco interesse dos alunos; o excesso de "burocracia" na escola para a disponibilização dos materiais didáticos no momento em que são solicitados pelos professores ou alunos; a falta de tempo para a reflexão sobre a prática docente, bem como sobre os critérios e objetivos relacionados ao uso de determinado material didático.

Observamos também a dificuldade que os professores apresentam na utilização de materiais didáticos provenientes das novas tecnologias, como o computador, a Internet e o uso de softwares. A não apropriação dos mecanismos de utilização desses materiais e da forma de aplicação ao ensino da disciplina que o professor leciona, impedem a utilização dos mesmos na sala de aula. Os objetos 
que fazem parte do dia-a-dia do professor, usados também em atividades sociais externas à vida escolar; ou seja, os objetos sociais que já foram apropriados pelos professores, como a TV, o vídeo e o rádio, são utilizados com mais freqüência e com mais facilidade na sala de aula.

A disciplina que o professor leciona e o conteúdo a ser ensinado na sala de aula exercem uma grande influência na escolha e utilização dos materiais didáticos. Alguns professores encontram facilidades na utilização de materiais didáticos em sua disciplina, outros revelam que muitas vezes não conseguem encontrar uma aplicabilidade. Notamos que a sala-ambiente onde é ensinada a disciplina de ciências está equipada com vários tipos de materiais didáticos, conforme o discurso do professor. Para o professor de ciências, a sala-ambiente tem propriciado bons resultados de aprendizagem e facilitado muito sua prática docente. Já os outros professores, apesar de destacarem a importância dos materiais didáticos no ensino e se mostrarem bem receptivos à utilização dos mesmos, apontam, em seus discursos, dificuldades nesta utilização e principalmente na organização da sala-ambiente como um espaço produtivo para o processo de ensino-aprendizagem.

Retornando a questão sobre autonomia docente e sua relação com os materiais didáticos, é válido também considerarmos que em algumas entrevistas os professores vêem o material didático como um elemento comprometedor da sua autonomia docente, não no que diz respeito ao material didático em si, mas sim quanto a forma como são levados a utilizarem o material didático em sala de aula. Se a política educacional está investindo na aquisição desses materiais, se os materiais didáticos são tomados como objetos importantes para a realização de um ensino de qualidade, a partir de um discurso também presente no ideário pedagógico, então os professores, como efetivadores das propostas educacionais, devem introduzir esses materiais em suas aulas. Os professores, muitas vezes, sentem-se pressionados por este discurso dominante a utilizar-se de um determinado material didático, pois sua postura frente a esta utilização poderá influenciar a maneira como seus superiores avaliam sua competência profissional ou mesmo os seus colegas de trabalho. Nestas falas, podemos exemplificar as opiniões docentes sobre isso.

Eu acho que ela dá e ao mesmo tempo ela tira. Porque se ela está dando, oferecendo e mandando os recursos é para que você use os recursos. Então, eu acho que tira um pouco a sua autonomia, a sua forma de trabalhar com os alunos. Se tem material na escola você tem que usar. Então, eu acho que ao mesmo tempo que dá ele tira esta autonomia. Você é cobrado a trabalhar com aquilo que eles estão oferecendo (PROFESSOR H).

No entanto, os professores entrevistados parecem não se preocupar com esses "olhares" e colocam o material didático num lugar subalterno a sua competência profissional, procurando maneiras de preservar e exercer esta autonomia, de forma a realizar um bom trabalho com seus alunos em sala de aula; como as seguintes palavras de alguns professores podem mostrar. Ser um bom professor não tem nenhuma dependência com a utilização ou não de um material didático. Não é o uso do material didático que faz o professor ser competente em sala de aula. Para a maioria dos professores entrevistados, o professor é o próprio material, o próprio instrumento capaz de ensinar de maneira satisfatória seus alunos através de sua competência profissional que engloba o conhecimento que possui sobre a disciplina que leciona, a sua postura frente ao ensino e o seu relacionamento com os alunos.

Ao perguntarmos aos professores sobre os cursos de capacitação, observamos em suas práticas discursivas que a formação continuada proposta pela política educacional não é vista de maneira positiva para o desenvolvimento da prática docente com o uso de materiais didáticos. Muitos professores, seis dos entrevistados, disseram não gostar das capacitações por essas não abordarem questões e dificuldades surgidas no cotidiano da sala de aula, estando afastadas da realidade vivida pelos professores e pelos alunos. Quanto ao uso do material didático, os professores revelaram que pouco tem se falado sobre a efetiva utilização desses materiais no ensino, quanto a forma de adaptá-los ao conteúdo ensinado em sala de aula, especificamente para cada disciplina. Já três dos professores entrevistados afirmaram que as capacitações têm auxiliado muito a sua prática docente na utilização de materiais didáticos no ensino das disciplinas que lecionam. 
Apesar de todos os professores opinarem ser de extrema importância a atualização do professor e a reflexão sobre a sua prática, procurando maneiras de aprimorá-la, seus discursos distinguem-se quanto o papel que os materiais didáticos desempenham no caminho desta mudança.

Para alguns professores, os materiais didáticos introduzidos na escola exerceram grande influência sobre sua maneira de ensinar e de preparar as suas aulas. Entre outros fatores, como a vontade de mudar e o questionamento sobre sua própria competência profissional, os materiais didáticos também foram apontados como elementos importantes nesta mudança.

Do outro lado estão os professores que acreditam que a mudança ocorrida em sua prática pedagógica não sofreu influência direta do investimento em materiais didáticos pela política educacional, mas sim que esta mudança se deu pelo próprio questionamento do professor sobre a sua maneira de ver o ensino e sua prática pedagógica. Com a existência ou não do material didático na sala de aula, esses professores sentem que mudaram suas concepções quanto a sua profissão e o seu papel no ensino.

Ao perguntarmos aos professores se a não utilização de materiais didáticos e a resistência ao uso de alguns deles podem comprometer o ensino, muitos responderam que esta resistência pode influenciar negativamente a aprendizagem dos alunos. Na opinião desses professores, os motivos desta resistência, principalmente quanto ao uso do computador, residem na falta de domínio para a manipulação e uso didático deste material, na falta de interesse e vontade de usar, na preferência por materiais didáticos que induzem a pouca movimentação e conversa dos alunos em sala de aula, já que as classes são numerosas. Outros professores revelaram que é necessário que o professor resista se perceber que o uso não facilitará sua prática docente, pois a utilização ou não de um material didático é irrelevante para o desenvolvimento de uma prática docente de sucesso.

\section{Considerações Finais}

É importante compreendermos que os professores são produtores de um discurso sobre os materiais didáticos, mas que suas práticas discursivas, suas concepções e sua prática docente refletem também outros discursos já ditos sobre esses materiais. Assim, os professores são sujeitos e objetos de discursos, contribuindo para a construção de um "regime de verdade", mas também gerando novas formas de se olhar para os materiais didáticos, no contexto do cotidiano escolar.

No decorrer da análise, observamos que o lugar e o papel que o material didático ocupa na prática docente diferem daqueles que a política educacional e os manuais estabelecem para o mesmo. As práticas discursivas docentes também destacam a importância que os materiais didáticos assumem na construção do conhecimento, facilitando a aprendizagem. Reiteram que esses objetos são capazes de deixar a aula mais estimulante, mais envolvente, aproximando o aluno do conhecimento; por esta razão os professores selecionam com cuidado os materiais didáticos que serão utilizados durante a aula. Contudo, a maioria dos professores entrevistados coloca, a priori, a figura do professor como o principal elemento capaz de ensinar os alunos, estando os materiais didáticos a serviço de sua prática pedagógica. A utilização ou não dos materiais didáticos não interferirá no alcance dos objetivos de aprendizagem, a competência docente é que será responsável por isto.

Concluímos que é extremamente perigoso afirmarmos que os professores são resistentes aos materiais didáticos, principalmente aos mais modernos. Nossa pesquisa possibilitou compreender que discursivamente os professores não são resistentes aos materiais didáticos, pois suas práticas discursivas estão repletas de concepções e saberes historicamente construídos sobre os materiais didáticos que reafirmam a importância de sua utilização na aprendizagem do aluno e na melhoria do ensino em geral.Talvez o que chamamos de resistência são apenas caminhos diferentes que os professores encontram para sanar as dificuldades que surgem na introdução de qualquer tipo de material novo em suas aulas, diferente daqueles que já parecem ser inerentes ao ato de ensinar: o giz, a lousa e o livro didático. 
No contexto vivido pelos professores, usar um material didático significa também exigir mais da prática docente, ter cuidado com o exercício da autonomia docente, apropriar-se de práticas escolares novas. São nesses caminhos alternativos e nos significados que os materiais didáticos assumem para os professores, e são tomados por esses como verdadeiros no cotidiano escolar, que o discurso docente, muitas vezes, entra em conflito com o discurso da política educacional; ao mesmo tempo que, também como esse, revela em suas práticas discursivas concepções do discurso pedagógico.

Para os professores, a formação sobre a utilização do material didático realiza-se na sala de aula, in locus, e o professor percebe o seu aprimoramento profissional em relação a esta utilização. Ao selecionar, planejar, utilizar o material didático que conhece muito bem, independente de ser um material visto como tradicional ou um material mais sofisticado e moderno, o professor sente-se realizado como profissional quando percebe que o material selecionado e utilizado por ele deu certo; ou seja, conseguiu facilitar a aprendizagem do aluno e principalmente estimulá-lo para a aquisição do conhecimento.

A autonomia docente em relação a utilização dos materiais didáticos é importante para a realização desta formação in locus, pois quando as idéias e ações não surgem dos próprios professores há uma tendência a inibição, ocorrendo somente uma reprodução das idéias dos outros de forma automática, isolada, pontual. Neste sentido, há necessidade de desafiarmos o educador a refletir sobre a sua prática, propiciando-lhe condições de reavaliá-la e reformulá-la. Esta possibilidade somente ocorrerá se dermos voz ao professor, levando-o a uma prática reflexiva.

Acreditamos que muitas das questões iniciais de pesquisas foram respondidas no decorrer do estudo que realizamos. No entanto, sabemos que ainda há muito que se discutir e analisar sobre os materiais didáticos no ensino e esperamos ter instigado essas discussões nas lacunas que não conseguimos preencher no desenvolvimento desse trabalho. Contudo, os resultados das análises realizadas conduzem-nos a pensar um pouco mais sobre esses materiais no cotidiano escolar; na maneira como os professores concebem esses materiais e apropriam-se deles em sua prática docente; nas implicações que surgem ao introduzir-se materiais no ensino, no que concerne a estrutura do sistema escolar e a prática docente; nas maneiras e possibilidades de preparar os professores para essas implicações, de forma que os mesmos possam olhar tanto as potencialidades dos objetos para o ensino quanto o exercício de sua autonomia docente na utilização desses objetos. Ao compreendermos os materiais didáticos no processo de desenvolvimento profissional do professor, abrimos possibilidades de superação de obstáculos que venham inibir o espaço de experimentação e o crescimento profissional a partir da utilização desses materiais em sala de aula.

\section{$\underline{\text { Referências Bibliográficas }}$}

CARBONNEAU, Michel; HÉTU, Jean-Claude (2001). Formação prática dos professores e nascimento de uma inteligência profissional. In: PAQUAY, Léopold; PERRENOUD, Philippe; ALTET, Marguerite; CHARLIER, Évelyne.(Orgs). Formando professores profissionais: quais estratégias? Quais competências? (p.67-79).Porto Alegre :Artemed.

FOUCAULT, Michel (2000). As palavras e as coisas. São Paulo: Martins Fontes.

FOUCAULT, Michel (2001). Microfísica do poder. Rio de Janeiro: Edições Graal.

GIMENO SACRISTÁN, J. (2000).O currículo: uma refelxão sobre a prática. Porto Alegre: Artmed. 
MINAYO, M.C.S. (2000). O desafio do conhecimento: pesquisa qualitativa em saúde. (p.99104/107-134). São Paulo: Hucitec; Rio de Janeiro: Abrasco.

TARDIF, Maurice. (2002).Saberes docentes e formação profissional. Petrópolis, RJ: Vozes. 